\title{
Dynamics of Intraindustry Trade and Labor-Market Adjustment
}

\author{
Marius Brülhart*
}

\begin{abstract}
This paper investigates some dynamic aspects of the "smooth adjustment hypothesis" that is commonly associated with intraindustry trade (IIT). The analysis is conducted on a panel of plant-level employment data and industry-level production and trade data for Ireland. Rates of intraindustry job turnover are used as a proxy for labor-market adjustment. Three findings stand out. First, a measure of marginal IIT is found to be more appropriate for the analysis of adjustment issues than the traditional static IIT index. Second, the effect of marginal IIT on labor-market adjustment is most significant in the short term, namely for indices calculated on one-year intervals and lagged by one year. Third, the most significant determinants of the intraindustry job turnover rate are sector-level plant concentration ratios and trade openness.
\end{abstract}

\section{Introduction}

There are two motivations for empirical research on intraindustry trade (IIT), the simultaneous import and export of very similar goods: (a) it is difficult to reconcile IIT with the predictions of neoclassical trade theory, and (b) IIT may herald comparatively smooth factor-market adjustment to trade liberalization. This paper examines aspects of the second issue, which is sometimes referred to as the "smooth adjustment hypothesis." Thanks to its intuitiveness this hypothesis has become widely accepted, but it has so far been subjected to little formal scrutiny.

A recent advance in this context was the development of dynamic IIT measures, labeled marginal IIT (MIIT), which conceptually relate more closely to adjustment processes than the traditional static indices. Progress was also made in linking trade data to sectorally disaggregated industrial statistics, which allows for direct tests of the correlation between (M)IIT and proxies for factor-market adjustment. ${ }^{1}$

Using data on manufacturing trade and job turnover in Ireland, this paper sheds light on three dynamic issues relating to the smooth-adjustment hypothesis. First, I review the case for using MIIT rather than IIT measures in analyses of adjustment. Second, I discuss the choice of the appropriate time horizon over which to calculate MIIT measures both conceptually and on the basis of empirical results. I find evidence that the MIIT-adjustment link works over relatively short time intervals. Third, I investigate the relative timing of trade and labor-market changes, and I find that the former tend to precede the latter.

An introductory review of the literature on the smooth-adjustment hypothesis is given in section 2. Section 3 sets out the empirical model and tests MIIT and static IIT measures. In section 4, I explore the issue of appropriate time intervals and lag structures. Section 5 concludes.

\footnotetext{
* Brülhart: Université de Lausanne, 1015 Lausanne, Switzerland. E-mail: Marius.Brulhart@hec.unil.ch. I am indebted to Anthony Murphy and Eric Strobl for their collaboration on earlier parts of the research. This paper has also benefited from suggestions made by two referees and by Robert Elliott, as well as by seminar participants at the Universities of Manchester, Nottingham, Liverpool, and Oxford. Part of the work on this paper was done while I was a Visiting Fellow at the Policy Institute, Trinity College Dublin. Their support is gratefully acknowledged.
} 


\section{Conceptual Issues in Trade and Labor-Market Dynamics}

\section{Measuring Intraindustry Trade}

IIT has traditionally been measured by the Grubel-Lloyd (GL) index:

$$
G L_{t}=\left(1-\frac{|X-M|}{(X+M)}\right)_{t},
$$

where $M$ stands for imports in a particular industry, $X$ represents corresponding exports, and $t$ is the reference year. This is a static measure, since it is based on trade data for one year only. ${ }^{2}$ Hamilton and Kniest (1991) have argued that the observation of a high proportion of IIT in one particular time period does not justify a priori any prediction of the likely pattern of change in trade flows. Even an observed increase in static IIT levels between two periods (positive $\Delta G L$ ) could "hide" a very uneven change in trade flows, akin to inter- rather than intra-industry adjustment. Motivated by this insight, a range of alternative measures have been developed to capture the MIIT concept empirically. ${ }^{3}$

In this paper, I retain the $A$ index developed in Brülhart (1994) as the preferred measure of MIIT:

$$
A_{I}=1-\frac{\left|\Delta_{I} X_{t}-\Delta_{I} M_{t}\right|}{\left|\Delta_{I} X_{t}\right|+\left|\Delta_{I} M_{t}\right|}
$$

where $\Delta$ denotes changes in constant prices, $t$ indicates the base year, and $I$ denotes the length of the time interval between the base and end years. One feature of this index is its similarity with the $G L$ coefficient. The $A$ index also varies between 0 and 1 , where 0 indicates that marginal trade in an industry is exclusively inter-industry and 1 indicates that it is entirely intra-industry, and the $A$ index shares most of the statistical properties of the $G L$ index. A share measure is preferred in the context of this paper to measures that are based on levels, such as the $C$ measure of Brülhart (1994) or UMCIT of Menon and Dixon (1997), because what we are interested in is the proportion of MIIT in total trade change, having controlled for the size of total trade in a sector.

The distinction between MIIT and IIT would appear superfluous if we found the two variables to be highly correlated in the data. However, Figures 1 and 2 clearly show that the $A$ index is unrelated to levels and first-differences of the $G L$ index in our Irish dataset (64 industries, 1977-91). The distinction between MIIT and IIT therefore seems relevant both conceptually and empirically.

\section{Choice of Time Interval}

The literature on MIIT has so far been concerned mainly with the identification of appropriate measures, and comparatively scant attention has been paid to questions of practical application. Given that (M)IIT measures are ultimately designed to guide policy-relevant empirical work, it is important that the conceptual analysis be complemented by research on practical relevance and on questions of empirical implementation. There are a number of practical issues which matter for MIIT measures in a similar way as they affect the analysis of static IIT. These include topics such as the choice of the level of sectoral disaggregation, weighting methods in summing results over base sectors, and the appropriateness of correction for aggregate trade imbalance. Most of these issues have been analysed comprehensively and authoritatively by 


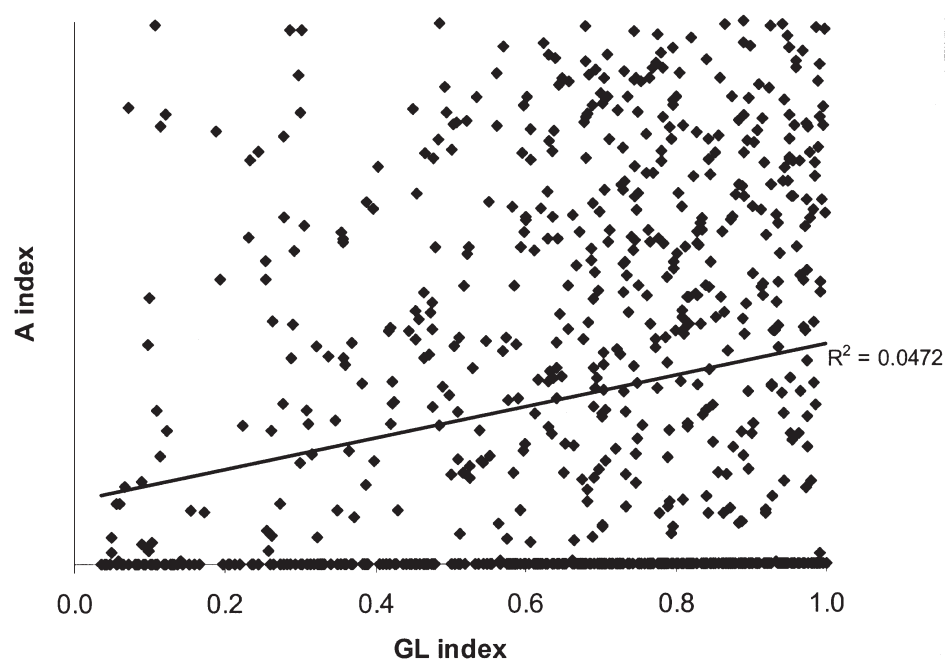

Figure 1. A and GL Indices: Scatter Plot and OLS Regression Line

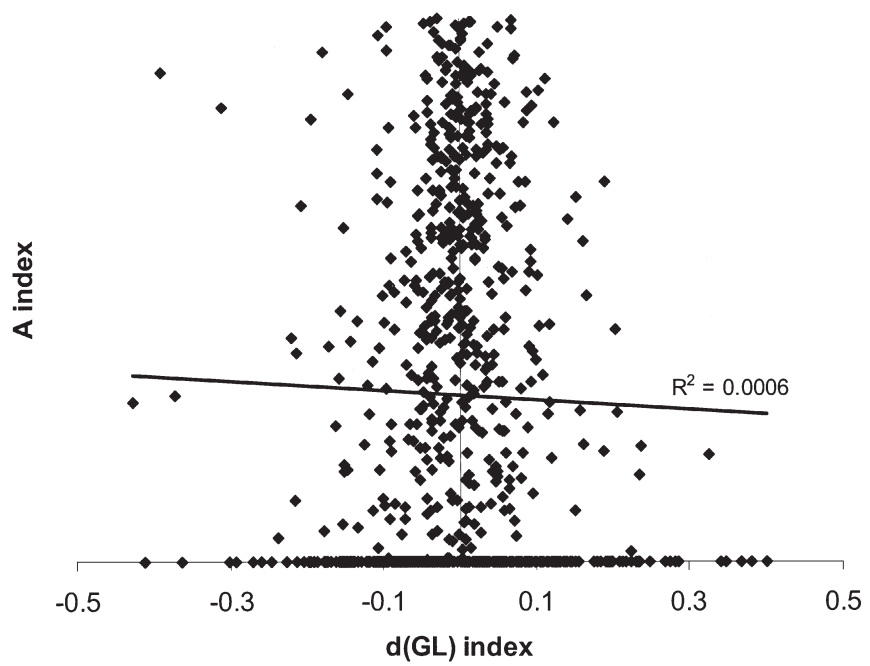

Figure 2. A and $\Delta G L$ Indices: Scatter Plot and OLS Regression Line

Greenaway and Milner (1986). There remain, however, some unexplored empirical questions relating to the appropriate measurement of MIIT. Two methodological issues are of specific relevance to MIIT: the choice of time interval for the calculation of MIIT measures, and the relative timing of trade and factor-market effects. It is on these aspects that I concentrate in this paper.

Measurement of MIIT indices necessitates a choice of the most appropriate time interval, $\Delta$. There is little to guide the analysis a priori in selecting the relevant time period; apart, perhaps, from some intuitive notion that medium-term changes in trade patterns are likely to correlate most strongly with factor-market changes. Observed 
short-term trade changes may be prone to noise and excess volatility (some real and some due to measurement error) that is unlikely to affect firms' hiring and investment decisions in a discernible way. On the other hand, in looking at long-term trade changes one might loose sight of the transitional processes implied by the smooth adjustment hypothesis. However, the delineation of the "medium term" remains an empirical question, which I explore in section 4.

Even before looking at data, however, it can be noted that the choice of time interval for MIIT measurement is likely to be crucial. This is due to a particular statistical feature of MIIT measures. Oliveras and Terra (1997) have shown that there is no systematic relationship between the $A$ index calculated over a certain time interval and $A$ indices calculated over constituent subintervals. The demonstration is straightforward. First, we can take the basic definition of the $A$ index for an interval $I$ starting in base year $t$ from equation (2), and apply the same formula to any subinterval $i$ and base year $s$ as follows:

$$
A_{i s}=1-\frac{\left|\Delta_{i} X_{s}-\Delta_{i} M_{s}\right|}{\left|\Delta_{i} X_{s}\right|+\left|\Delta_{i} M_{s}\right|}, \quad \text { where } \sum i=I, i>0 \text {, and } t \leq s<t+I \text {. }
$$

Next, define:

$$
B_{i s}=\frac{\Delta_{i} X_{s}-\Delta_{i} M_{s}}{\left|\Delta_{i} X_{s}\right|+\left|\Delta_{i} M_{s}\right|}, \quad \text { and } \quad w_{i s}=\frac{\left|\Delta_{i} X_{s}\right|+\left|\Delta_{i} M_{s}\right|}{\sum_{i}\left(\left|\Delta_{i} X_{s}\right|+\left|\Delta_{i} M_{s}\right|\right)},
$$

where $B_{i s}$ is the "trade performance index" of Brülhart (1994), and $w_{i s}$ assigns tradechange weights to subintervals.

If the $A$ index were a well-behaved weighted average of constituent subinterval $A$ indices, the following relationship should hold:

$$
A_{I t}=\sum_{i} w_{i} A_{i s} \text {. }
$$

However, as demonstrated by Oliveras and Terra (1997), this regularity is only obtained if

$$
\operatorname{sg}(B)=\operatorname{sg}\left(B_{i s}\right) \forall i s
$$

that is if the net balance of trade changes has the same sign in all subintervals. In other words, equation (5) holds, and a systematic link between the $A$ index and its subinterval "components" exists, only if there is a continuous improvement/deterioration of the trade balance over subintervals in the sector at hand. Conversely, if net improvements and net deteriorations in the sectoral trade balance appear in different subintervals, no generalized relationship can be derived between the MIIT index for the full time interval, $A_{I t}$, and the subinterval measures $A_{i s}$. Inspection of most series of international trade data shows that net year-on-year changes in sectoral trade flows are rarely continuous, and the resulting dynamic "disjointedness" of the $A$ index therefore needs to be taken into consideration in empirical application.

\section{Timing of Trade and Labor-Market Effects}

A second issue of empirical dynamics concerns the intertemporal sequencing of trade adjustments on the one hand, and factor-market adjustments on the other hand. Since the adjustment issue is mostly discussed with respect to reallocations in labor markets, this paper abstracts from adjustments in markets for other production factors. It is well 
known that changes in firms' payrolls tend to follow changes in sales only with a certain time lag, as firms absorb sales variations in the short term through variations in stocks or temporary changes in hours worked ("hoarding"). ${ }^{4}$ Since there are no established theoretical or empirical priors on the size of this time lag, this is a fruitful object for more in-depth empirical scrutiny.

\section{Testing the Smooth-Adjustment Hypothesis}

\section{An Empirical Model of Intraindustry Trade and Job Turnover}

In this section I present an empirical test of the smooth-adjustment hypothesis, concentrating on adjustment in terms of plant-level employment changes. A fully specified empirical model must comprise three elements: (i) a dependent variable to represent labor-market adjustment; (ii) an independent variable representing (M)IIT; and (iii) a set of independent variables to control for other exogenous influences on labor-market adjustment.

I use the index for intrasectoral job turnover of Davis and Haltiwanger (1992) as the dependent variable. ${ }^{5}$ Derivation of this measure is as follows. Gross changes in plant-level job numbers within a particular industry are summed separately for plant births and expansions (POS) and for plant deaths and contractions (NEG) over the period starting in $t$ and spanning the interval $\Delta_{I}$ :

$$
\begin{aligned}
& P O S_{t}=\sum_{p} \Delta_{I} E_{t p} \quad \text { for } \Delta_{I} E_{t p}>0, \\
& N E G_{t}=\sum_{p}\left|\Delta_{I} E_{t p}\right| \text { for } \Delta_{I} E_{t p}<0,
\end{aligned}
$$

where $E$ stands for the number of employees and $p$ denotes plants. From this, one can derive the industry-level measure of excess job reallocation:

$$
\text { WITHIN }_{t}=\left(\text { POS }_{t}+N E G_{t}-\left|P O S_{t}-N E G_{t}\right|\right) /\left(P O S_{t}+N E G_{t}\right),
$$

where WITHIN $_{t}$ is the share of total plant-level job reallocation that is due to job reallocation in excess of net aggregate employment change of the particular industry. Like the IIT measures presented above, WITHIN takes values between zero and one. The left endpoint corresponds to instances where all plants within the sector experience either net job creation or job destruction; and the right endpoint corresponds to instances where the net change in job numbers of the sector is zero, and hence every job lost is offset by a job created simultaneously in the same sector.

The rationale for using WITHIN is its assumed relationship to labor-market adjustment costs. However, WITHIN is not a direct measure of labor adjustment costs, as it contains no information about flows into and out of unemployment, nor about relative wage changes and "adjustment services". ${ }^{6}$ Nevertheless, the assumptions that need to hold for WITHIN to be a suitable inverse proxy for labor-market adjustment costs seem plausible. For WITHIN to be a valid proxy, labor should in general move more easily within than between industries. I cannot subject this crucial component of the smooth-adjustment hypothesis to an empirical test with the available data, but this assumption is strongly supported by empirical work in labor economics. Evidence that it is costlier for workers to move across industries instead of switching job within industries has been reported by Fallick (1993), Kletzer (1996), Neal (1995), and Shin (1997) for the United States, and by Greenaway et al. (1999) for the UK. In a comparative 
study for the US and the UK, Haynes et al. (1999) show that the likelihood of a displaced worker moving sectors relative to the likelihood of being re-employed in the original sector increases with the duration of the unemployment spell. This is compelling evidence that adjustment costs are higher for movers than for stayers. The link between intraindustry job turnover and low adjustment costs is therefore well documented. ${ }^{7}$

Moving on to the explanatory side of the model, there are three variables on which one can formulate well-founded priors.

1. One may expect highly concentrated industries to experience relatively low intrasectoral employment reallocation. Conversely, the larger the number of plants within an industry, the higher will be the share of intraindustry labor turnover, ceteris paribus. The explanation is in two parts. First, simple arithmetic suggests that if an industry contains only a few plants, there may be less scope for intraindustry job moves between plants. Second, if plant and firm numbers are correlated, competitive pressures are likely to be weaker in sectors with small plant numbers, and plantlevel payrolls are likely to be less volatile, because, for instance, larger profit margins allow for the absorption of negative demand shocks without labor shedding. Hence, it seems plausible to expect a negative relationship between WITHIN and a measure of plant concentration.

2. Second, based on similar reasoning, there is likely to be a positive relationship between WITHIN and trade exposure. If openness to trade means greater intensity of competition, then plant-level employment changes are likely to be required more frequently in order for firms to adapt to changing competitive positions vis-à-vis their competitors in low-margin activities. The expectation is therefore of a positive relationship between WITHIN and a measure of trade openness.

3. Most importantly, I have strong priors about the coefficients on the IIT variable. According to the smooth-adjustment hypothesis, the adjustment pressures induced by trade openness will be mitigated to the extent that trade flows are intraindustry. If the MIIT literature is correct and relevant, the GL index and WITHIN should be unrelated, but one would expect to find a significant positive relationship, ceteris paribus, between WITHIN and a measure of MIIT.

The first two of these expected relationships have been found to hold in a study of job turnover in Swedish industry by Andersson et al. (1998).

I consider four additional explanatory variables, which are known to be important in shaping industrial employment patterns in Ireland, but for which there are no clearcut priors on expected coefficient signs. These variables are sectoral wages, technology intensity, exposure to foreign ownership, and changes in apparent demand. Hence, the baseline model is as follows:

$$
\begin{aligned}
\text { WITHIN_LOG }_{x t}= & \alpha+\beta_{1} \text { CONC }_{x t}+\beta_{2} T R A D E_{x t}+\beta_{3} W A G E_{x t}+\beta_{4} T E C H_{x t} \\
& +\beta_{5} \text { FOREIGN }_{x t}+\beta_{6} \Delta A D_{x t}+\beta_{7} I I T_{x t}+\lambda_{t}+\varepsilon_{x t}
\end{aligned}
$$

where

$$
\text { WITHIN_LOG }=\ln (\text { WITHIN } /[1-\text { WITHIN }]),
$$

and $C O N C$ is the four-plant concentration ratio, TRADE is imports plus exports as a share of production, WAGE is the average wage, TECH is the share of blue-collar workers in the total workforce, FOREIGN is the employment share of majority foreign-owned plants, $\triangle A D$ is the change in apparent consumption, IIT is either the $G L$ or the $A$ index, $\lambda$ is a time dummy, and $\varepsilon$ is an i.i.d. random error term. The 
subscripts $x$ and $t$ refer to industries and years, respectively. The logit transformation on WITHIN in equation (11) is performed in order to avoid problems due to the boundedness of the index. In the computation of WITHIN_LOG, values of 0 are set as 0.001 and values of 1 as 0.999 . A fixed-effects panel data model is preferred to random effects, because the dataset consists of essentially the population of all Irish manufacturing industries.

The dataset is an industry-level panel of job turnover, trade, and other potentially relevant variables for the Irish manufacturing sector using three sources: a plant-level employment dataset provided by the Irish Agency for Enterprise and Technology (Forfás), the Census of Industrial Production (CIP) published by the Irish Central Statistical Office, and a trade dataset provided by Eurostat. The panel is balanced, with observations on 64 industries for fourteen years, 1977 to 1990. A detailed description of the dataset can be found in Brülhart et al. (1998).

\section{Year-on-Year Regression Results}

Table 1 gives raw correlation coefficients among the variables of equation (10), with all the first-difference variables computed over one-year intervals. The first column, reporting correlations between WITHIN_LOG and the explanatory variables, supports all our priors: positive correlation with the $A$ index (if lagged by one period), no correlation with the $G L$ index or $\triangle G L$, and the expected correlations with $C O N C$ and $T R A D E$ (lagged by one period).

Estimates of partial correlations in the full fixed-effects panel data model are reported in Table 2. The dependent variable WITHIN_LOG as well as the $A$ index are again calculated over one-year intervals. Variables representing concentration ratios, trade exposure, and IIT are lagged by one year, since that structure gave consistently the most significant results in panel regressions as well as for bivariate correlations. I find strong confirmation of the priors on $C O N C$ and $T R A D E$ in all specifications. These results confirm the intuitive expectation that competitive pressures, induced by large plant numbers and openness to trade, lead to increased rates of job reallocation within industrial sectors.

Table 2 also confirms that it is not possible to find significant relationships between any definition of the $G L$ index and intraindustry job turnover, whilst a modestly significant positive coefficient appears in the case of the one-year lagged $A$ index. In regressions (1) to (3) of Table 2, I have estimated the full model with three different variables for IIT: the one-year-lagged $G L$ index, first-differences in the $G L$ index, and the one-year-lagged $A$ index. Only in the last case is a significant partial correlation found. These results emerge with remarkable consistency across alternative specifications. $^{8}$

Columns (4) and (5) of Table 2 report estimates of a parsimonious model consisting only of the variables on which we have theoretical priors. In addition to its congruence with a priori expectations, this specification is found to be very robust in a range of specification tests in Brülhart et al. (1998), and I therefore retain it here. Specification (4) shows that the one-year-lagged $A$ index exhibits the predicted relationship with the dependent variable in the parsimonious version too. In column (5), a multiplicative interaction variable of lagged $A$ indices and TRADE is added to the parsimonious model. One might expect MIIT to have a stronger impact in sectors that are relatively exposed to international trade, and hence the coefficient on the interaction term would be positive. However, the estimated regression coefficient on the interaction variable is only weakly positive, and dominated by the separate trade and MIIT variables. Other 
Table 1. Raw Correlations Among Year-on-Year Variables

\begin{tabular}{|c|c|c|c|c|c|c|c|c|c|c|c|c|c|}
\hline & $\begin{array}{l}\text { WITHIN } \\
\quad \text { LOG }\end{array}$ & $\begin{array}{l}\text { CONC } \\
\text { lagged }\end{array}$ & $\begin{array}{l}\text { TRADE } \\
\text { lagged }\end{array}$ & $W A G E$ & TECH & FOREIGN & $\triangle A D$ & $G L$ & $\begin{array}{c}G L \\
\text { lagged }\end{array}$ & $\Delta G L$ & $A$ & A lagged & $\begin{array}{c}(A * T R A D E) \\
\text { lagged }\end{array}$ \\
\hline $\begin{array}{l}\text { WITHIN }_{-} \\
\text {LOG }\end{array}$ & 1 & & & & & & & & & & & & \\
\hline $\begin{array}{l}\text { CONC } \\
\text { lagged }\end{array}$ & $-0.39 * *$ & 1 & & & & & & & & & & & \\
\hline $\begin{array}{r}\text { TRADE } \\
\text { lagged }\end{array}$ & $0.16^{* *}$ & $-0.20 * *$ & 1 & & & & & & & & & & \\
\hline$W A G E$ & $-0.15^{* *}$ & $0.15^{* *}$ & $-0.15^{* *}$ & 1 & & & & & & & & & \\
\hline TECH & -0.01 & -0.04 & $-0.16^{* *}$ & 0.05 & 1 & & & & & & & & \\
\hline FOREIGN & $-0.15^{* *}$ & $0.38 * *$ & $0.21 * *$ & -0.05 & $-0.17 * *$ & 1 & & & & & & & \\
\hline$\triangle A D$ & 0.02 & $-0.13 * *$ & $0.26 * *$ & $-0.09 * *$ & $-0.06^{*}$ & $0.06^{*}$ & 1 & & & & & & \\
\hline$G L$ & -0.02 & 0.03 & $-0.15^{* *}$ & -0.01 & $0.13^{* *}$ & $0.13 * *$ & $-0.11 * *$ & 1 & & & & & \\
\hline GL lagged & -0.03 & 0.04 & $-0.14 * *$ & -0.01 & $0.14^{* *}$ & $0.13 * *$ & $-0.07 *$ & $0.92 * *$ & 1 & & & & \\
\hline$\Delta G L$ & 0.02 & -0.02 & -0.03 & -0.01 & -0.04 & -0.01 & $-0.09 * *$ & $0.18^{* *}$ & $-0.22 * *$ & 1 & & & \\
\hline$A$ & -0.02 & -0.01 & 0.04 & $-0.06^{*}$ & -0.04 & $0.08 *$ & $0.07 *$ & $0.22 * *$ & $0.23 * *$ & -0.03 & 1 & & \\
\hline A lagged & $0.07 *$ & -0.01 & 0.05 & -0.05 & $-0.07 *$ & $-0.09 *$ & -0.01 & $0.21 * *$ & $0.22 * *$ & -0.01 & $0.14 * *$ & 1 & \\
\hline $\begin{array}{l}(A \\
\quad * T R A D E) \\
\quad \text { lagged }\end{array}$ & $0.13 * *$ & $-0.12 * *$ & $0.71 * *$ & $-0.09 * *$ & $-0.18^{* *}$ & $0.21 * *$ & $0.20 * *$ & 0.03 & 0.04 & -0.01 & $0.08 *$ & $0.44 * *$ & 1 \\
\hline
\end{tabular}

Note: The number of observations ranges from 768 to 896 .

**Indicates statistical significance at the $1 \%$ level of confidence, and *indicates statistical significance at the $10 \%$ level. 
Table 2. Labor Turnover and Intraindustry Trade: Year-on-Year Fixed-Effects Panel Estimates

\begin{tabular}{|c|c|c|c|c|c|c|c|c|c|c|}
\hline \multirow[b]{2}{*}{ Explanatory variables } & \multicolumn{2}{|c|}{$\begin{array}{c}(1) \\
\text { GL index }\end{array}$} & \multicolumn{2}{|c|}{$\begin{array}{c}(2) \\
\Delta G L \text { index }\end{array}$} & \multicolumn{2}{|c|}{$\begin{array}{l}(3) \\
A \text { index }\end{array}$} & \multicolumn{2}{|c|}{$\begin{array}{c}(4) \\
\text { A index, } \\
\text { parsimonious model }\end{array}$} & \multicolumn{2}{|c|}{$\begin{array}{c}\text { (5) } \\
\text { A index interacted, } \\
\text { parsimonious model }\end{array}$} \\
\hline & Beta & $t$-statistic & Beta & $t$-statistic & Beta & $t$-statistic & Beta & $t$-statistic & Beta & $t$-statistic \\
\hline CONC lagged & -0.349 & $-7.44 * *$ & -0.349 & $-7.40 * *$ & -0.343 & $-7.16^{* *}$ & -0.370 & $-8.78 * *$ & -0.371 & $-8.80 * *$ \\
\hline$T R A D E$ lagged & 0.091 & $2.90 * *$ & 0.091 & $2.99 * *$ & 0.098 & $3.08^{* *}$ & 0.087 & $2.94 * *$ & 0.080 & $1.95^{*}$ \\
\hline$W A G E$ & -0.087 & $-1.99 *$ & -0.087 & $-1.98 *$ & -0.090 & $-1.94^{*}$ & & & & \\
\hline TECH & -0.010 & -0.32 & -0.011 & -0.33 & -0.005 & -0.16 & & & & \\
\hline FOREIGN & -0.031 & -0.70 & -0.031 & -0.74 & -0.044 & -1.03 & & & & \\
\hline$\triangle A D$ & -0.050 & $-2.40^{*}$ & -0.050 & $-2.37 *$ & -0.043 & $-1.99 *$ & & & & \\
\hline GL lagged & -0.002 & -0.04 & & & & & & & & \\
\hline$\Delta G L$ & & & -0.001 & -0.04 & & & & & & \\
\hline A lagged & & & & & 0.063 & $1.80 *$ & 0.064 & $1.84 *$ & 0.060 & 1.37 \\
\hline$(A * T R A D E)$ lagged & & & & & & & & & 0.010 & 0.18 \\
\hline No. of explanatory variables & \multicolumn{2}{|c|}{19} & \multicolumn{2}{|c|}{19} & \multicolumn{2}{|c|}{19} & \multicolumn{2}{|c|}{15} & \multicolumn{2}{|c|}{16} \\
\hline No. of observations & \multicolumn{2}{|c|}{832} & \multicolumn{2}{|c|}{832} & \multicolumn{2}{|c|}{768} & \multicolumn{2}{|c|}{768} & \multicolumn{2}{|c|}{768} \\
\hline Adjusted $R^{2}$ & \multicolumn{2}{|c|}{0.162} & \multicolumn{2}{|c|}{0.162} & \multicolumn{2}{|c|}{0.168} & \multicolumn{2}{|c|}{0.166} & \multicolumn{2}{|c|}{0.161} \\
\hline
\end{tabular}

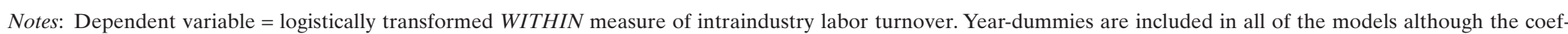

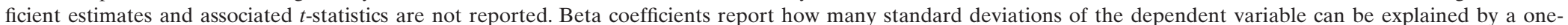
standard-deviation movement in the explanatory variable. The $t$-statistics shown are based on heteroskedasticity-consistent (White-adjusted) standard errors.

**Indicates statistical significance at the $1 \%$ level of confidence, and *indicates statistical significance at the $10 \%$ level. 
interactions of the IIT variables also failed to produce significant results. The empirical specifications used later in this paper therefore omit interaction terms.

In conclusion, panel data regressions on a dataset for Irish industry suggest that yearon-year MIIT relates positively to the rate of intraindustry job turnover, while static IIT is unrelated to this proxy for labor-market adjustment. This evidence supports the MIIT version of the smooth-adjustment hypothesis. However, I find that two other variables, plant concentration ratios and trade exposure, exert even stronger influence on the rate of intraindustry job turnover than shares of MIIT.

\section{Dynamics}

\section{Time Intervals}

In light of the purported sensitivity of MIIT measures to the size of the underlying time interval, I subject this issue to explicit scrutiny. The one-year periods used so far constitute the lower-bound possible interval size when applied to annual data, and they therefore correspond to the "short term" in the dataset used here. The question thus raised is: How are the results found in section 3 affected if we extend the length of the underlying time intervals?

The dataset covers 14 years (1977-91). Hence, the lower and upper bounds on feasible intervals are 2 and 14 respectively. In the empirical definition of these intervals, a choice must be made about the construction of the relevant base and end periods. It seems reasonable to postulate that those two subintervals should be nonoverlapping and of equal length. This still leaves room for alternatives. Taking the example of the 14-year interval, one could either define year 1 as the base period and year 14 as the end period; or, at the other extreme, the average over years 1-6 as the base period and the average over years $8-14$ as the end period. I have opted for the latter version, since this is most congruent with the aim of eliminating short-term data volatility as the interval is extended.

The construction of medium-term A indices can be expressed formally as follows:

$$
A_{\overline{B E}}=1-\frac{\left|\left(X_{E}-X_{B}\right)-\left(M_{E}-M_{B}\right)\right|}{\left|\left(X_{E}-X_{B}\right)\right|+\left|\left(M_{E}-M_{B}\right)\right|},
$$

where $B$ and $E$ stand for the base and end periods, respectively. Using the notation of section 3, which labels the first year of the interval as $t$ and the number of years in the total interval as $I$, define:

$$
X_{B}=\frac{\sum_{y=t}^{t+\operatorname{int}(I / 2)} X_{y}}{\operatorname{int}(I / 2)}, \text { and } X_{E}=\frac{\sum_{y=t+I-\operatorname{int}(I / 2)}^{t+I} X_{y}}{\operatorname{int}(I / 2)},
$$

assuming downward rounding in the integer function. Base- and end-period imports are defined equivalently.

In a similar vein, the other variables of my empirical model need to be recalculated for the relevant time interval. In the parsimonious model, the variables WITHIN, $C O N C$, and $T R A D E$ require adaptation. For $C O N C$ and $T R A D E$, this simply means averaging over the interval I. WITHIN is recalculated on the basis of year-on-year POS and $N E G$ summed over the relevant time interval $I$ (cf. equations (7)-(9)).

Some descriptive statistics confirm the sensitivity of the MIIT measure to the choice of interval. I have first calculated correlations across the 64 sample industries between, 
on the one hand, WITHIN calculated over the full 14-year interval, and, on the other hand, year-on-year values of WITHIN averaged over the 14 years. ${ }^{9}$ The correlation coefficient is 0.48 and statistically significant at the $0.01 \%$ level. The same exercise was then conducted with $A$ indices. The cross-industry correlation coefficient between, on the one hand, $A$ indices calculated over the 14-year interval and, on the other hand, mean year-on-year $A$ indices is 0.29 and statistically significant at the $5 \%$ level. Hence, there is a linear relationship in the data between MIIT measures over a certain interval and those of subintervals, but that relationship is rather weak. Another way of capturing this feature of MIIT indices is to look at their year-on-year serial correlations. Table 1 reports correlations of current values with their lags for the $G L$ and $A$ indices. The one-year autocorrelation coefficient for the $G L$ index is 0.92 , but for the $A$ index it is a mere 0.14. All these descriptive statistics support the conceptual analysis of Oliveras and Terra (1997), by confirming that the $A$ index-and hence the results reported in section 3-are sensitive to the choice of time interval.

This sensitivity becomes even more apparent when the full regression model is reestimated for variables calculated over different time intervals. Table 3 reports the result of the parsimonious model estimated for 2-, 5- and 10-year intervals. While the control variables $C O N C$ and $T R A D E$ are robust to those variations, the MIIT variable is not. Extending the time interval to two years (i.e., inserting a one-year gap in year-on-year computations of $A$ ) leaves a positive sign on the estimated coefficient for the $A$ index, but statistical significance is lost. Indeed, the $A$ index is never statistically significant when the size of the interval exceeds one year, and the estimated relationship with the intraindustry job turnover rate is (implausibly) negative in regressions (2) and (3) of Table 3.

This result also emerges from Figure 3, which reports beta coefficients on the three regressors of the parsimonious model for all interval sizes between 1 and 10 years (an asterisk denotes statistical significance at the $10 \%$ level). The chart visualizes the extent to which the effects of $C O N C$ and TRADE exceed those of MIIT, and it again becomes apparent that the significance of the $A$ index hinges on the length of the chosen time interval. The coefficient on the $A$ index is statistically insignificant for all interval sizes above one year. Moreover, seven of the eight interval sizes above two years produce negative (though statistically insignificant) coefficients on the $A$ index-against our theoretical priors.

These results suggest that the relevant period over which to compute MIIT measures in analyses of trade-induced adjustment is shorter than one might have expected. In the dataset used here, one-year intervals are the only period over which the $A$ index has a significant impact on the rate of intraindustry job turnover.

\section{Lag Structure}

For the reasons outlined in section 2, the sequencing issue also deserves explicit investigation. I have therefore re-estimated the model with four different lag structures on the two trade variables: contemporaneous changes with the regressand, one-year lag, two-year lag, and three-year lag. ${ }^{10}$ Table 4 reports results for four corresponding regression runs, all based on one-year time intervals for WITHIN and A. CONC and TRADE again emerge statistically significant and with the expected signs throughout, while the $A$ index is sensitive to the size of the lag. Contemporaneity is rejected, as the coefficient on the $A$ index without lag is statistically insignificant and negative. Similarly, any lag that is larger than one year seems too long. Whilst the model with two-year lags still produces a positive but statistically insignificant coefficient estimate on the $A$ 
Table 3. Fixed-Effects Panel Estimates of Parsimonious Model With Varying Time Intervals

\begin{tabular}{|c|c|c|c|c|c|c|}
\hline \multirow[b]{2}{*}{ Explanatory variables } & \multicolumn{2}{|c|}{$\begin{array}{c}\text { (1) } \\
\text { 2-year intervals }\end{array}$} & \multicolumn{2}{|c|}{$\begin{array}{c}\text { (2) } \\
5 \text {-year intervals }\end{array}$} & \multicolumn{2}{|c|}{$\begin{array}{c}\text { (3) } \\
\text { 10-year intervals }\end{array}$} \\
\hline & Beta & $t$-statistic & Beta & $t$-statistic & Beta & t-statistic \\
\hline CONC lagged one year & -0.325 & $-8.09 * *$ & -0.308 & $-7.56 * *$ & -0.298 & $-5.84 * *$ \\
\hline TRADE lagged one year & 0.065 & $2.21 *$ & 0.100 & $2.74 * *$ & 0.095 & 1.37 \\
\hline A lagged one year & 0.037 & 1.01 & -0.033 & -0.87 & -0.052 & -0.90 \\
\hline No. of explanatory variables & \multicolumn{2}{|c|}{15} & \multicolumn{2}{|c|}{12} & \multicolumn{2}{|c|}{7} \\
\hline No. of observations & \multicolumn{2}{|c|}{768} & \multicolumn{2}{|c|}{512} & \multicolumn{2}{|c|}{256} \\
\hline Adjusted $R^{2}$ & \multicolumn{2}{|c|}{0.110} & \multicolumn{2}{|c|}{0.119} & \multicolumn{2}{|c|}{0.105} \\
\hline
\end{tabular}

Notes: Dependent variable = logistically transformed WITHIN measure of intraindustry labor turnover. See also the note to Table 2.

Table 4. Fixed-Effects Panel Estimates of Parsimonious Model With Varying Lags

\begin{tabular}{|c|c|c|c|c|c|c|c|c|}
\hline \multirow[b]{2}{*}{ Explanatory variables } & \multicolumn{2}{|c|}{$\begin{array}{c}(1) \\
\text { No lag }\end{array}$} & \multicolumn{2}{|c|}{$\begin{array}{c}\text { (2) } \\
\text { 1-year lag }\end{array}$} & \multicolumn{2}{|c|}{$\begin{array}{c}\text { (3) } \\
\text { 2-year lag }\end{array}$} & \multicolumn{2}{|c|}{$\begin{array}{c}\text { (4) } \\
\text { 3-year lag }\end{array}$} \\
\hline & Beta & $t$-statistic & Beta & $t$-statistic & Beta & $t$-statistic & Beta & $t$-statistic \\
\hline CONC lagged one year & -0.375 & $-9.04 * *$ & -0.370 & $-8.78 * *$ & -0.391 & $-8.65 * *$ & -0.387 & $-7.95 * *$ \\
\hline$T R A D E$ (varying lags) & 0.078 & $2.78 * *$ & 0.087 & $2.94 * *$ & 0.075 & $2.41 *$ & 0.079 & $2.50 *$ \\
\hline$A$ (varying lags) & -0.023 & -0.71 & 0.064 & $1.84^{*}$ & 0.014 & 0.40 & -0.004 & -0.10 \\
\hline No. of explanatory variables & \multicolumn{2}{|c|}{16} & \multicolumn{2}{|c|}{15} & \multicolumn{2}{|c|}{14} & \multicolumn{2}{|c|}{13} \\
\hline No. of observations & \multicolumn{2}{|c|}{832} & \multicolumn{2}{|c|}{768} & \multicolumn{2}{|c|}{704} & \multicolumn{2}{|c|}{640} \\
\hline Adjusted $R^{2}$ & \multicolumn{2}{|c|}{0.161} & \multicolumn{2}{|c|}{0.166} & \multicolumn{2}{|c|}{0.171} & \multicolumn{2}{|c|}{0.163} \\
\hline
\end{tabular}

\footnotetext{
Notes: Dependent variable = logistically transformed WITHIN measure of intraindustry labor turnover; one-year intervals. See also the note to Table 2.
} 


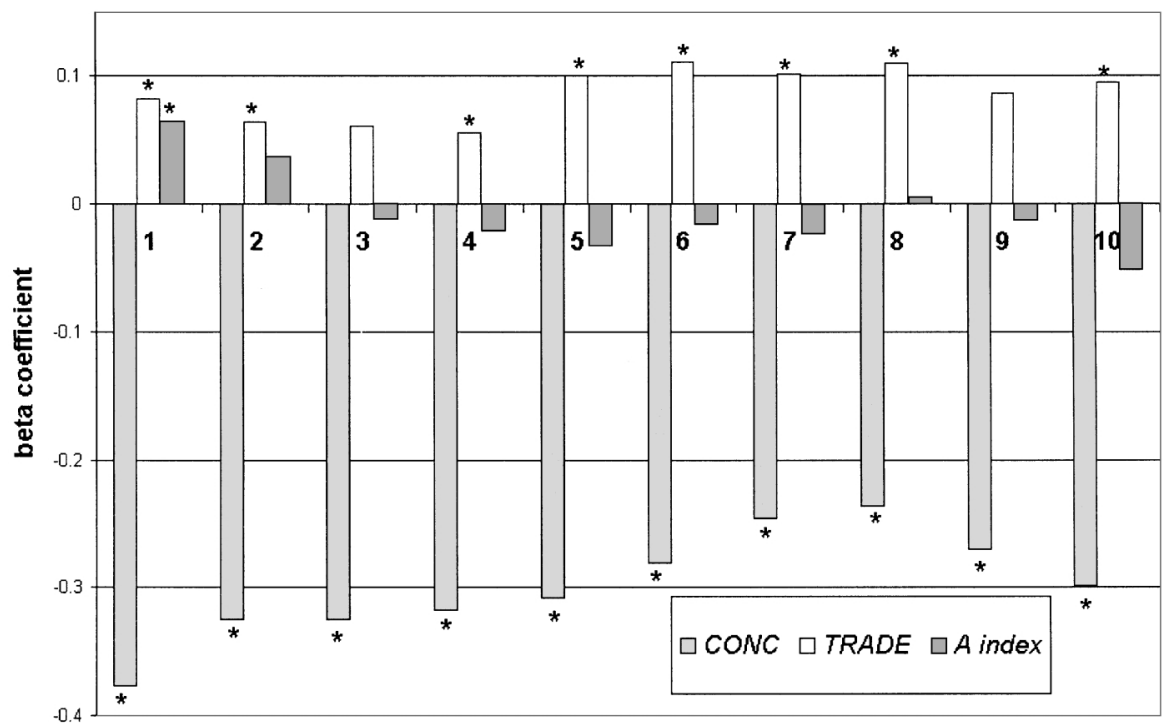

interval size

Figure 3. Beta Coefficients on CONC, TRADE, and A, with Varying Intervals

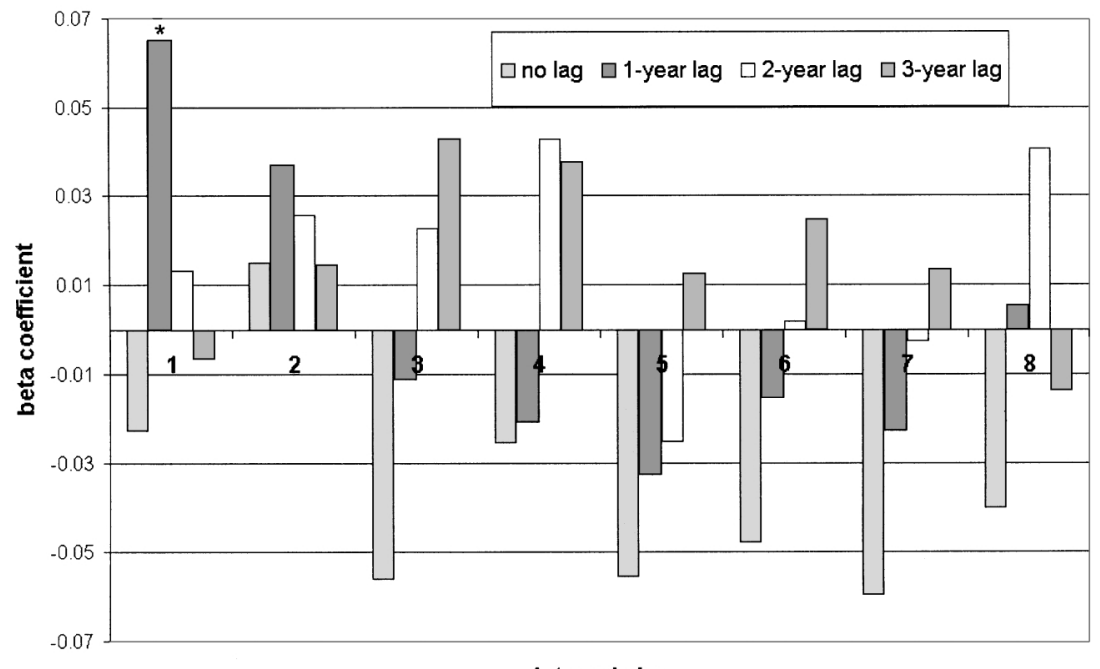

interval size

Figure 4. Beta Coefficients on the A Index, with Varying Lags and Time Intervals

index, the point estimate turns negative and insignificant in the version with threeyear lags.

A picture is again given to visualize the effect of varying the dynamics of the model. Figure 4 tracks beta coefficients on the $A$ index for the four lag structures across eight different sizes of the time interval. Only one specification stands out in yielding a statistically significant positive coefficient estimate on $A$, namely the original year-on-year 
model with one-year lags used in section 3. Contemporaneity as well as lags above one year are consistently rejected. ${ }^{11}$

In short, sensitivity analysis on various dynamic structures of the basic model suggests that MIIT measures computed over one-year intervals and lagged by one year relate most significantly to labor-market reallocation in the sense of the smoothadjustment hypothesis.

\section{Conclusions}

I have explored some dynamic aspects of the "smooth-adjustment hypothesis" that is commonly associated with intraindustry trade. The analysis draws on a panel of Irish plant-level industrial employment data and of corresponding industry-level production and trade statistics for the 1980s. A concept borrowed from the empirical labor economics literature, the rate of intraindustry job turnover, is used as a proxy for labormarket adjustment.

Three questions were investigated. First, I explored the relevance of the traditional static IIT measure compared with that of an index measuring marginal IIT (MIIT). In some regression specifications, MIIT did appear with the expected sign and significance. However, no significant relationship was found between the proxy for labor adjustment and any variant of static IIT. Second, the appropriate size of the time intervals for MIIT and corresponding labor-market adjustment was investigated. The data clearly favor the shortest time period, namely year-on-year intervals. Third, I explored the relative timing of trade and labor-market changes by assuming different lag structures. The results suggest that labor-market effects follow changes in trade structure with a one-year lag.

It should be noted that by far the most significant determinants of the rate of intraindustry job turnover throughout was a sector-level measure of market concentration, followed by a measure of openness to trade. The share of MIIT in trade changes seems to have some bearing on the pattern of labor market adjustment in the short term, but over a long-term horizon these effects are swamped by changes in the intensity of competition among plants within a certain industry, be this trade-induced or not.

\section{References}

Andersson, Linda, Ola Gustafsson, and Lars Lundberg, "Structural Change, Competition and Job Turnover in the Swedish Manufacturing Industry 1964-96," FIEF working paper 148, Trade Union Institute for Economic Research, Stockholm (1998).

Azhar, Abdul K., Robert J. R. Elliott, and Chris Milner, "Static and Dynamic Measurement of IIT and Adjustment: A Geometric Reappraisal," Weltwirtschaftliches Archiv 134 (1998): 404-22.

Baldwin, Robert E., John H. Mutti, and J. David Richardson, "Welfare Effects on the United States of a Significant Multilateral Tariff Reduction," Journal of International Economics 36 (1980):223-38.

Brülhart, Marius, "Marginal Intra-Industry Trade: Measurement and Relevance for the Pattern of Industrial Adjustment," Weltwirtschaftliches Archiv 130 (1994):600-13.

— - "Marginal Intra-Industry Trade and Trade-Induced Adjustment: A Survey," in M. Brülhart and R. C. Hine (eds), Intra-Industry Trade and Adjustment: The European Experience, London: Macmillan (1999).

Brülhart, Marius, Anthony Murphy, and Eric Strobl, "Intra-Industry Trade and Job Turnover," GLM research paper 98/4, Centre for Research on Globalisation and Labour Markets, University of Nottingham (1998). 
Davis, Steven J. and John Haltiwanger, "Gross Job Creation, Gross Job Destruction and Employment Reallocation,” Quarterly Journal of Economics 107 (1992):819-64.

Fallick, Bruce C., "The Industrial Mobility of Displaced Workers," Journal of Labor Economics 11 (1993):302-23.

Feenstra, Robert C. and Tracy R. Lewis, "Trade Adjustment Assistance and Pareto Gains from Trade,” Journal of International Economics 36 (1994):201-22.

Greenaway, David and Chris Milner, The Economics of Intra-Industry Trade, Oxford: Basil Blackwell (1986).

Greenaway, David, Robert C. Hine, Chris Milner, and Robert Elliott, "Adjustment and the Measurement of Marginal Intra-Industry Trade," Weltwirtschaftliches Archiv 130 (1994):418-27.

Greenaway, David, Richard Upward, and Peter Wright, "Sectoral Mobility in UK Labour Markets," GLM research paper 99/1, Centre for Research on Globalisation and Labour Markets, University of Nottingham (1999).

Hamilton, Clive and Paul Kniest, "Trade Liberalisation, Structural Adjustment and IntraIndustry Trade: A Note," Weltwirtschaftliches Archiv 127 (1991):356-67.

Haynes, Michelle, Richard Upward, and Peter Wright, "Smooth and Sticky Adjustment: A Comparative Analysis of the US and UK," GLM research paper 99/7, Centre for Research on Globalisation and Labour Markets, University of Nottingham (1999).

Kletzer, Lori G., "The Role of Sector-Specific Skills in Post-Displacement Earnings," Industrial Relations 35 (1996):473-90.

Levinsohn, James, “Employment Responses to International Liberalization in Chile," Journal of International Economics, 47 (1999):321-44.

Lovely, Mary and Doug Nelson, "Factor-Market Adjustment to Inter-Industry and Intra-Industry Trade in a Division of Labour Model," mimeo, Syracuse and Tulane Universities (1999).

Menon, Jayant and Peter B. Dixon, "Intra-Industry versus Inter-Industry Trade: Relevance for Adjustment Costs," Weltwirtschaftliches Archiv 133 (1997):164-9.

Neal, Derek, "Industry-Specific Human Capital: Evidence from Displaced Workers," Journal of Labor Economics 13 (1995):653-77.

Nickell, Stephen J., "Dynamic Models of Labour Demand," in: O. Ashenfelter and R. Layard (eds), Handbook of Labour Economics, Vol. 1, Amsterdam: North-Holland (1986).

Oliveras, Joaquín and Inés Terra, "Marginal Intra-Industry Trade Index: The Period and Aggregation Choice," Weltwirtschaftliches Archiv 133 (1997):170-9.

Shin, Kwanho, "Inter- and Intrasectoral Shocks: Effects on the Unemployment Rate," Journal of Labor Economics 15 (1997):376-401.

Thom, Rodney and Moore McDowell, "Measuring Marginal Intra-Industry Trade," Weltwirtschaftliches Archiv 135 (1999):48-61.

\section{Notes}

1. See Brülhart (1999) for an overview.

2. For the purpose of this analysis, it is useful to think of annual trade volumes as if they were stocks rather than flows.

3. Hamilton and Kniest (1991), Greenaway et al. (1994), Brülhart (1994), Menon and Dixon (1997), and Thom and McDowell (1999) have all proposed different measures of MIIT. For discussions, see Azhar et al. (1998), and Brülhart (1999). Lovely and Nelson (1999) have given the MIIT-adjustment link a theoretical underpinning.

4. For a survey of labor-demand responses to changes in product demand, see Nickell (1986).

5. For other recent applications of this job-turnover measure in the context of international trade, see Levinsohn (1999) and Andersson et al. (1998).

6. On different types of trade-induced adjustment costs, see Baldwin et al. (1980), and Feenstra and Lewis (1994).

7. An additional condition for accepting WITHIN as a useful proxy is that plant-level job turnover should correlate positively with total job turnover, since one of the main scenarios of smooth adjustment to IIT is where workers are redeployed within plants. Whilst it seems 
plausible to assume a positive correlation, we cannot verify it directly in our plant-level dataset.

8. Results are available from the author.

9. In the case of $C O N C$ and $T R A D E$, the two definitions coincide, and the correlation is 1 by definition.

10. The one-year lag on $C O N C$ was maintained throughout.

11. Figure 4 shows that 2- and 3-year lags applied to $A$ indices calculated over intervals of 2-4 years yield the expected positive coefficients, but they are never statistically significant even at the $10 \%$ level. 